\title{
Proposta de protocolo com produto pré-lavagem na remoção de sujidades inorgânicas em instrumentais odontológicos
}

Efficacy of pre-cleaning product in the removal of inorganic dirt in dental instruments - Case report Eficacia del producto de limpieza previa en la eliminación de suciedad inorgánica en instrumentos dentales: reporte de caso Danila de OLIVEIRA ${ }^{1}$

Francielle Soares Venturelli BARRADO ${ }^{2}$

Pedro Henrique Silva GOMES-FERREIRA ${ }^{3}$

Fernando Isquierdo de SOUZA ${ }^{4}$

${ }^{1}$ Departamento de Materiais Odontológicos e Prótese, Faculdade de Odontologia de Araçatuba, UNESP, Univ. Estadual Paulista, 16015-050 Araçatuba, SP, Brasil ${ }^{2}$ Curso de Enfermagem, Campus Bandeirantes, UENP, Universidade Estadual do Norte do Paraná 86360-000 Bandeirantes-PR, Brasil

${ }^{3}$ Departamento de Cirurgia e Clínica Integrada, Faculdade de Odontologia de Araçatuba, UNESP, Univ. Estadual Paulista, 16015-050 Araçatuba, SP, Brasil ${ }^{4}$ Curso de Odontologia, Campus Jacarezinho, UENP, Universidade Estadual do Norte do Paraná 86400-000 Jacarezinho-PR, Brasil

\section{Resumo}

Durante os procedimentos odontológicos são utilizados diversos produtos como resinas, cimentos, adesivos, entre outros, e após a utilização deixam sujidades inorgânicas de difícil remoção, principalmente se a limpeza não for realizada imediatamente ou logo após o uso. O presente trabalho objetivou analisar a efetividade de um produto pré-limpeza aplicado após a utilização da espátula para resina, espátula 24, pote dappen e placa de vidro expostos às diferentes sujidades inorgânicas. Em todos os casos, o produto pré-limpeza mostrou-se eficaz em manter a superfície úmida durante 1 hora, possibilitando fácil remoção da sujidade inorgânica na etapa de limpeza, dispensando o uso de ação abrasiva sobre as peças, preservando a integridade dos instrumentais.

Descritores: Consultórios Odontológicos; Instrumentos Odontológicos; Detergentes; Tensoativos.

\section{Abstract}

During dental procedures various products such as resins, cements, adhesives and others are used and after use they are with inorganic dirt difficult to remove, especially if the cleaning is not performed immediately or soon after use. The present paper aimed to analyze the effectiveness of a pre-cleaning product applied after the use of the spatula for resin, spatula 24, dappen pot and glass plate exposed to different inorganic dirt. In all cases, the pre-cleaning product proved effective in keeping the surface moist for 1 hour, allowing easy removal of the inorganic dirt in the cleaning step, avoiding the use of abrasive action on the parts, preserving the integrity of the instruments.

Descriptors: Dental Offices; Dental Instruments; Detergents; Surface-Active Agents.

\section{Resumen}

Durante los procedimientos dentales, se utilizan diversos productos, como resinas, cementos, adhesivos y otros, y después de su uso son difíciles de eliminar con suciedad inorgánica, especialmente si la limpieza no se realiza inmediatamente o poco después de su uso. El presente artículo tuvo como objetivo analizar la efectividad de un producto de limpieza previa aplicado después del uso de la espátula para la resina, la espátula 24, la olla y la placa de vidrio expuesta a diferentes impurezas inorgánicas. En todos los casos, el producto de limpieza previa demostró ser eficaz para mantener la superficie húmeda durante 1 hora, lo que permite eliminar fácilmente la suciedad inorgánica en la etapa de limpieza, evitando el uso de acción abrasiva en las piezas y preservando la integridad de los materiales.

Descriptores: Consultorios Odontológicos; Instrumentos Dentales; Detergentes; Tensoactivos.

\section{INTRODUÇÃO}

A limpeza é uma das etapas do Processamento de Produtos para Saúde, o qual é o conjunto de ações relacionadas à pré-limpeza, recepção, limpeza, secagem, avaliação da integridade e funcionalidade, preparo, desinfecção ou esterilização, armazenamento e distribuição para as unidades consumidoras ${ }^{1}$. A limpeza é a etapa fundamental do processamento dos produtos para saúde para garantir o seu reuso ${ }^{2}$, e é definida como a remoção mecânica de sujidades com o intuito de reduzir a carga microbiana, matéria orgânica e inorgânica, a fim de garantir o processo de desinfecção e esterilização e a manutenção da vida útil do produto para saúde ${ }^{1,3}$, sendo que todo material deve ser limpo imediatamente após o uso e, caso isso não seja possível, deve-se evitar o ressecamento da sujidade $^{1,3-6}$.

A pré-limpeza possui como objetivo impedir a aderência e o ressecamento da sujidade na superfície para facilitar o processo de limpeza, reduzir o nível de contaminação e proteger o operador durante o manuseio do material e deve ser executada imediatamente após o término do procedimento $^{7-10}$. No mercado atual existem produtos específicos para a pré-limpeza e umectação de produtos para saúde, estes são soluções pronto para o uso e com baixa formação de espuma para prevenir a aderência de matéria orgânica, no entanto, eles são mais frequentemente indicados e utilizados em ambientes hospitalares ${ }^{4}{ }^{4}$

Quando relacionado à área odontológica, sabe-se que durante os procedimentos são utilizados diversos produtos, tais como as resinas compostas e acrílicas, cimentos provisórios e definitivos, adesivos, materiais de moldagem, ceras, pastas de polimento e acabamento, entre outros. Eles podem ser manipulados e/ou utilizados em blocos de uso descartáveis ou em recipientes não descartáveis como as placas de vidro, sendo que após a utilização existem sujidades inorgânicas de difícil remoção, principalmente se a limpeza não for realizada imediatamente após o uso ${ }^{11-13}$.

Levando em consideração que existem produtos específicos para pré-limpeza que auxiliam na etapa de limpeza, em paralelo a dificuldade da realização desta etapa na área odontológica, o presente trabalho objetivou analisar e relatar a efetividade de um produto pré-limpeza, comercialmente disponível, aplicado após a utilização da espátula para resina, espátula 24 , pote dappen e placa de vidro expostos à diferentes sujidades inorgânicas. 


\section{MATERIAL E MÉTODO}

Após a utilização de placa de vidro (Placa de vidro polida, Golgran, São Paulo, São Paulo, Brasil) e espátula 24 (Espátula simples n ${ }^{\circ}$ 24, Golgran, São Paulo, São Paulo, Brasil) para a manipulação de cimento provisório (Temp CEM NE, Coltene, Rio de Janeiro, Rio de Janeiro, Brasil) foi borrifado sobre a placa de vidro o produto pré-limpeza à base de Tensoativos não iônicos, umectantes, sequestrante, acidificante, isotiazolinona, espessante e água purificada qsp. (Stelclean Plus, Labnews, Mogi Guaçu, São Paulo, Brasil) e mantido, em temperatura ambiente, por 1 hora. Após, seguiu o processo de limpeza com o detergente enzimático (Neozime, Labnews, Mogi Guaçu, São Paulo, Brasil), enxágue, secagem e esterilização (Figura 1A-D).

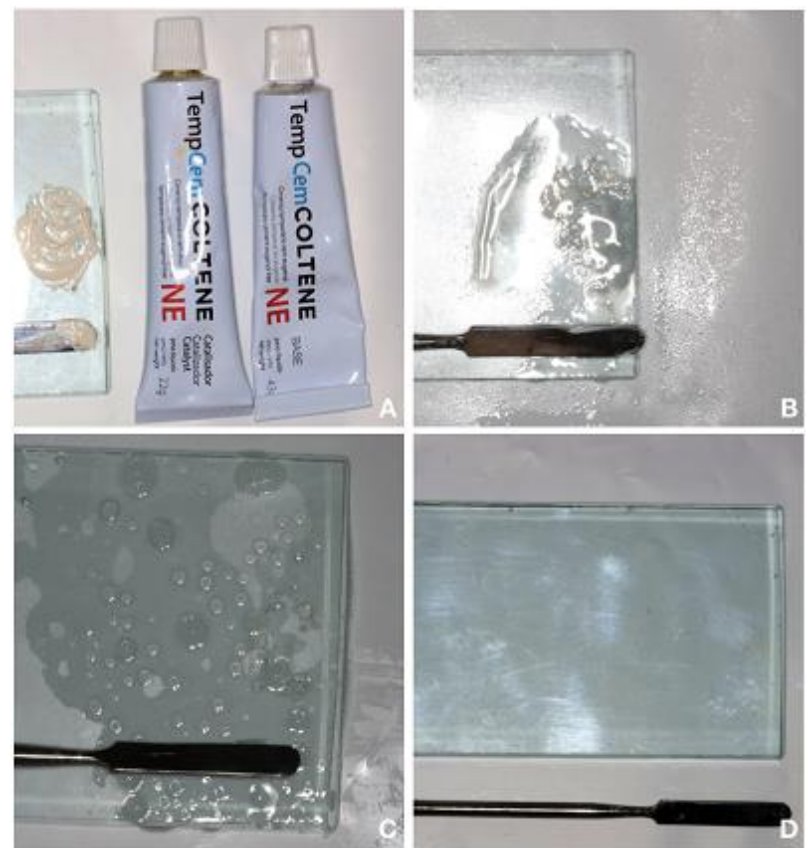

Figura 1: A - Placa de vidro e espátula 24 com o cimento provisório manipulado. B - Placa de vidro e espátula 24 com o detergente pré limpeza. C - Limpeza da placa de vidro e espátula 24 após 1 hora. D Placa de vidro e espátula 24 antes da esterilização.

Após a utilização de pote dappen (Pote dappen de vidro, Golgran, São Paulo, São Paulo, Brasil) e espátula 24 (Espátula simples no 24, Golgran, São Paulo, São Paulo, Brasil) para a manipulação de resina acrílica (Dencôr, Clássico, São Paulo, São Paulo, Brasil) foi borrifado sobre a placa de vidro o produto pré-limpeza (Stelclean Plus, Labnews, Mogi Guaçu, São Paulo, Brasil) e mantido, em temperatura ambiente, por 1 hora. Após, seguiu o processo de limpeza com o detergente enzimático (Neozime, Labnews, Mogi Guaçu, São Paulo, Brasil), enxágue, secagem e esterilização (Figura 2A-D).

Após a utilização de espátula para resina (Espátula Dupla Millennium, Golgran, São Paulo, São Paulo, Brasil) com resina composta (Filtek Z250 XT, 3M ESPE, St. Paul, MN, USA) foi borrifado sobre a espátula o produto pré-limpeza (Stelclean Plus, Labnews, Mogi Guaçu, São Paulo, Brasil) e mantido, em temperatura ambiente, por 1 hora. Após, seguiu o processo de limpeza com o detergente enzimático (Neozime, Labnews, Mogi Guaçu, São Paulo, Brasil), enxágue, secagem e esterilização (Figura 3A-D).

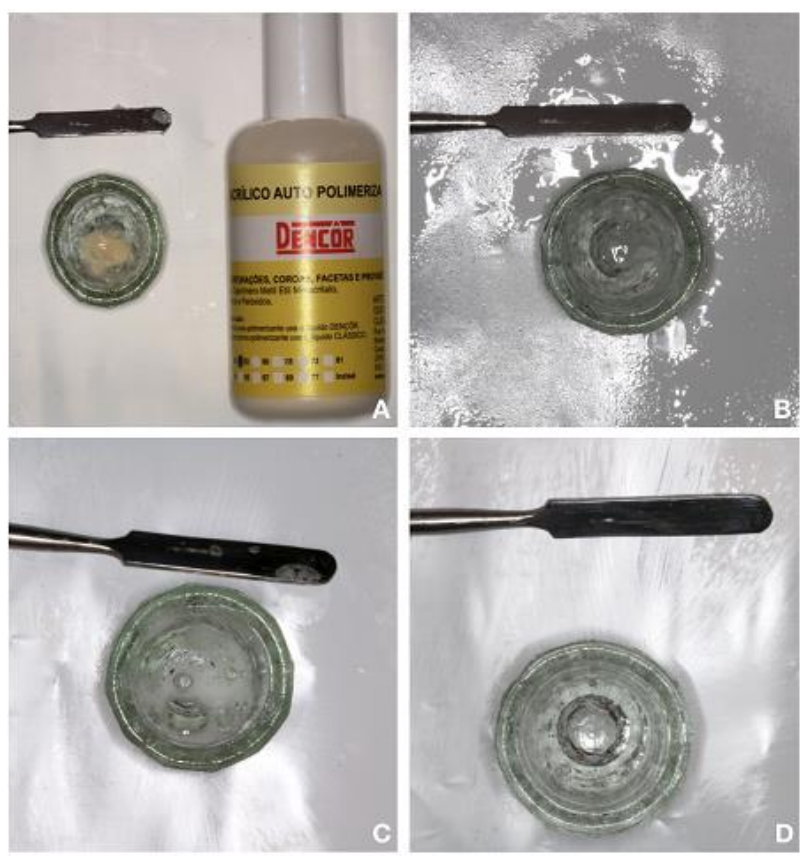

Figura 2: A - Pote dappen e e espátula 24 com a resina acrílica. B Pote dappen e e espátula 24 com o detergente pré-limpeza. C: Limpeza do pote dappen e espátula 24 após 1 hora. D: Pote dappen e e espátula 24 antes da esterilização.

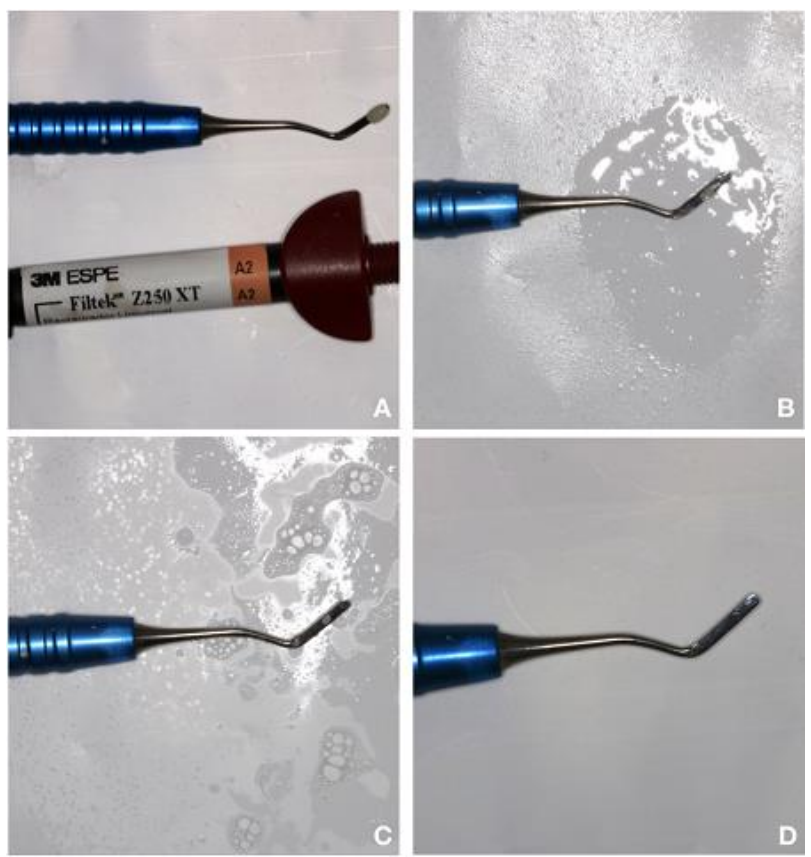

Figura 3: A - Espátula para resina com a resina composta. B Espátula para resina com o detergente pré-limpeza. C - Limpeza da espátula para resina após 1 hora. D - Espátula para resina antes da esterilização.

\section{RESULTADOS E DISCUSSÃO}

Em todas as situações de uso propostas, o produto pré-limpeza mostrou-se eficaz em manter a superfície úmida durante 1 hora e otimizou as etapas subsequentes de limpeza, secagem e esterilização.

O processamento de produto para saúde compreende a limpeza e a desinfecção ou esterilização, os quais podem ser realizados na 
Central de Material Esterilizado (CME) de serviços odontológicos e deve seguir o fluxo conforme Figura $4^{1}$.

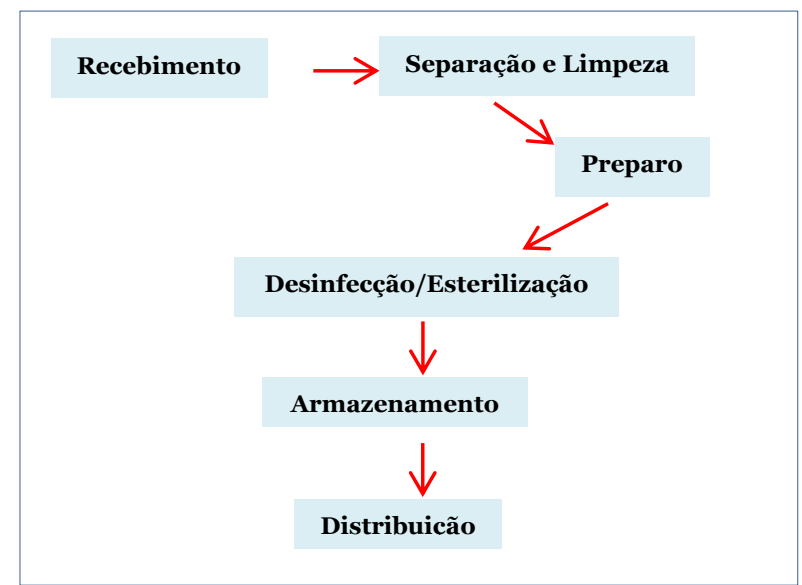

Figura 4: Fluxo do processamento de produto para saúde em Central de Material esterilizado (CME) ${ }^{1}$.

O consultório odontológico individual (área mínima de $9 \mathrm{~m}^{2}$ ) pode dispensar a CME e possuir no mesmo ambiente uma bancada com pia e equipamento de esterilização, desde que seja estabelecido rotinas de assepsia e barreira técnica com os materiais a serem esterilizados ${ }^{1}$

No processamento de produtos para saúde a pré-limpeza e a limpeza são as primeiras etapas a serem realizadas, com isso o profissional que está realizando deve ser capacitado para esta atividade, pois os instrumentais devem ser limpos com as melhores práticas e possuir bom funcionamento, este é o primeiro passo para fornecer materiais seguros para uso no paciente ${ }^{2,3,6}$.

A remoção mecânica de sujidades deve ser realizada imediatamente após o uso do produto para saúde para garantir o processo de desinfecção ou esterilização e a vida útil do mesmo ${ }^{5,8,14,15}$, esta prática pode também contribuir com a prevenção da formação de biofilme ${ }^{6,16}$, no entanto, devido a rotina de trabalho os instrumentais são muitas vezes limpos somente após o final do expediente. Quando relacionado à Odontologia, sabe-se que existem além das sujidades orgânicas, uma grande quantidade de sujidades inorgânicas após as consultas odontológicas. Principalmente nos procedimentos de Dentística e Prótese são utilizados muitos produtos com alto grau de adesão aos instrumentais, como as resinas compostas e acrílicas e os cimentos definitivos ou temporários ${ }^{17}$, alguns testados no presente trabalho.

Atualmente existe disponível no mercado diversas marcas de produtos pré-limpeza, com composições e apresentações distintas. Segundo a bula do produto pré-limpeza utilizado neste trabalho, ele "é um detergente pronto uso para pré-lavagem que previne a aderência de matéria orgânica na superfície interna e externa dos materiais médicos hospitalares. Possui formulação com $\mathrm{pH}$ neutro e de baixa espuma, evita o ressecamento de sangue e formação de biofilme, facilitando a remoção da sujidade no processo de limpeza e preserva a integridade fisica do instrumental ${ }^{\prime 18}$. Apesar da indicação do produto ser para sujidade de origem orgânica, houve o interesse em testar em sujidade de origem inorgânica com produtos de uso frequente em consultórios odontológicos pois, como citado acima, muitas vezes o processamento do produto para saúde não é realizado imediatamente após o término do atendimento e com isso gera incrustações de difícil remoção ${ }^{11-13,17}$.

Nos produtos e instrumentais testados no presente trabalho, com intervalo de 1 hora entre as etapas de pré-limpeza e limpeza, foi possível observar um resultado positivo do produto prélimpeza, semelhante aos resultados com sujidade orgânica, ou seja, manteve a superfície do produto para saúde úmida, e com isso facilitou a etapa convencional de limpeza com detergente enzimático e não foram necessários meios adicionais de remoção da sujidade inorgânica, com consequente preservação da integridade e vida útil dos instrumentais odontológicos, no entanto, outras marcas comerciais do produto pré-limpeza devem ser testadas nas mesmas condições para verificar se apresentam o mesmo desempenho.

\section{CONSIDERAÇÕES FINAIS}

A utilização do produto pré-limpeza em instrumentais odontológicos com sujidade inorgânica, utilizado neste estudo, mostrou-se eficaz em manter a superfície úmida, possibilitando fácil remoção deste tipo de sujidade na etapa de limpeza, dispensando o uso de ação abrasiva sobre as peças, preservando a integridade dos instrumentais.

\section{REFERÊNCIAS}

1. Brasil. Ministério da Saúde. Agência Nacional de Vigilância Sanitária. Serviços Odontológicos: Prevenção e Controle de Riscos. Brasília: Ministério da Saúde, 2006. 156 p.

2. Spruce L. Back to basics: instrument cleaning. AORN J. 2017;105(3):292-99.

3. Sociedade Brasileira de Enfermeiros de Centro Cirúrgico, Recuperação Anestésica e Centro de Material e Esterilização (SOBECC). Diretrizes de práticas em enfermagem cirúrgica e processamento de produtos para saúde. 7 ed. São Paulo: SOBECC; 2017.

4. EDLO. Recomendações para limpeza de instrumentais pré-esterilização. Disponível em: http://www.edlo.com.br. Acesso em 2 agosto 2018.

5. CDC. Recommended infection-control practices for dentistry, 1993. MMWR 1993;42(No. RR8).Disponível em: https://www.cdc.gov/ $\mathrm{mmwr} / \mathrm{PDF} / \mathrm{rr} / \mathrm{rr} 4208$.pdf . Acesso em 2 agosto 2018. 
6. Cowperthwaite L, Holm RL. Guideline implementation: surgical instrument cleaning. AORN J. 2015;101(5):542-49

7. Brasil. Ministério da Saúde. Agência Nacional de Vigilância Sanitária. Resolução RDC n. 15, de 15 de março de 2012. Dispõe sobre requisitos de boas práticas para o processamento de produtos para saúde e dá outras providências [Internet]. Brasília; 2012. Disponível em: http://www.anvisa.gov.br. Acesso em 2 agosto 2018.

8. AST (Association of Surgical Technologists). Standards of Practice for the Decontamination of Surgical Instruments. Disponível em: https://www.ast.org/AboutUs/Sterilization_and_D isinfection/. Acesso em 2 agosto 2018.

9. Bhatnagar S, Bagga DK, Sharma P, Kumar P, Sharma R, Singh V. Infection control strategy in orthodontic office. Eur J Gen Dent. 2013;2:1-7

10.Secker TJ, Pinchin HE, Hervé RC, Keevil CW. Efficacy of humidity retention bags for the reduced adsorption and improved cleaning of tissue proteins including prion-associated amyloid to surgical stainless steel surfaces. Biofouling. 2015;31(6):535-41.

11. Smith A, Letters S, Lange A, Perrett D, McHugh S, Bagg J. Residual protein levels on reprocessed dental instruments. J Hosp Infect. 2005; 61(3):237-41.

12. Smith A, Dickson M, Aitken J, Bagg J. Contaminated dental instruments. J Hosp Infect. 2002;51(3):233-35.

13. Miller CH, Tan CM, Beiswanger MA, Gaines DJ, Setcos JC, Palenik CJ. Cleaning dental instruments: measuring the effectiveness of an instrument washer/disinfector. Am J Dent. 2000;13(1):39-43.

14.Bagg J, Smith AJ, Hurrel D, McHugh S, Irvine G. Pre-sterilisation cleaning of re-usable instruments in general dental practice. Br Dent J. 2007; 202(9):E22.

15.Rutala WA, Weber DJ. Disinfection and sterilization in health care facilities: an overview and current issues. Infect Dis Clin North Am. 2016;30(3):609-37.

16. Bourdon L. RP first look: new recommended practices for cleaning and care of surgical instruments. AORN J. 2014;100(6):C1, C8-9.

17.Franz A, Bristela M, Stauffer F. Reprocessing of dental instruments in washer-disinfectors: does a representative test soil exist in dentistry? GMS Krankenhhyg Interdiszip. 2012;7(1):Doc13.

18.Labnews. Stelclean Plus. Disponível em: http://www.labnews.ind.br. Acesso em 2 agosto 2018.

\section{CONFLITO DE INTERESSES}

Os autores declaram não haver conflitos de interesse.

\section{AUTOR PARA CORRESPONDENCIA}

\section{Fernando Isquierdo de Souza}

fernando.isquierdo@uenp.edu.br

Submetido em 05/12/2018

Aceito em 24/05/2019 